\title{
Arbor
}

\section{La investigación biomédica}

\author{
Víctor de Lorenzo Prieto
}

Arbor CLXVI, 653 (Mayo 2000), 17-36 pp.

En este artículo se repasan brevemente algunas de las grandes transformaciones que ha sufrido la Biología Experimental en la última década y su repercusión en la Investigación Biomédica en el CSIC. Se diferencian las nuevas tecnologías (cuyo penúltimo avance es la robotización de operaciones altamente especializadas), de los nuevos esquemas organizativos dirigidos a una alta productividad científica y material. Finalmente se ofrece una visión de las fortalezas y debilidades del CSIC para afrontar las demandas de la investigación biológica en el nuevo siglo y se discuten algunas posibles líneas de actuación. En la opinión del autor, no hay mayor reto en estos momentos para el CSIC que el generar nuevas estructuras organizativas lo suficientemente flexibles como para responder en tiempo real a los cambios acelerados que experimenta la investigación biomédica a nivel mundial.

\section{Introducción}

La Biología Molecular es la ciencia con mayor impacto en la sociedad de este último cuarto de siglo. Si la investigación Física y Química de finales del XIX y comienzos del XX sentó las bases para el desarrollo explosivo de las comunicaciones, de los fármacos y de los nuevos materiales que caracterizan nuestra forma de vida, la Biología Experimental es sin duda alguna la frontera del conocimiento en nuestra época y el origen de cambios de todo tipo en el futuro no muy lejano. La otra gran frontera del conocimiento actual, la astrofísica, no tiene aún ni por asomo el efecto en la vida diaria de la investigación Biomédica 
y de su hija mayor, la Biotecnología, en millones de personas de nuestro planeta. La Biología Molecular ha dejado de ser una Ciencia más entre otras para ser el referente de otras muchas disciplinas que van mas allá de las Ciencias Naturales tradicionales (Botánica, Ecología, Zoología, Microbiología etc.). La generalización de las técnicas y los conceptos de la Biología Molecular no sólo ha cambiado radicalmente la Medicina y la Farmacología sino que está afectando decisivamente las bases de las Humanidades tradicionales. Ningún psicólogo, antropólogo o sociólogo puede ignorar hoy lo que nos dice la neurofisiología, la secuenciación del genoma humano o la sociobiología sobre el hombre o la sociedad. Estos cambios y su impacto social se han exacerbado en los últimos diez años y raro es el día que los medios no lo reflejan. Las hormonas recombinantes, las plantas transgénicas, los tejidos creados in vitro, el diagnóstico prenatal, los xenotransplantes, las nuevas terapias anti-cáncer, la utilización forense de la reacción en cadena de la polimerasa (PCR) son sólo unos pocos ejemplos de productos y técnicas que nacen de la Biología Molecular y que se han instalado entre nosotros para siempre.

¿Cual ha sido el papel del CSIC en este contexto, sobre todo en los últimos 10 años? Por su cobertura de todo el territorio del Estado, su organización centralizada y sus criterios más estrictos de selección del personal científico, la Biología Experimental ha sido, a pesar de numerosas limitaciones, una de las joyas de la corona de la Institución. La creación del Centro de Investigaciones Biológicas (CIB) en 1958 marca un hito en la historia de la ciencia Biológica española, ya que este centro ha sido a lo largo de más de 40 años la casa matriz de numerosos desarrollos y migraciones para fundar otros institutos del CSIC. En este sentido, dos Centros claves, fueron el Instituto de Enzimología y Patología Molecular (1970), rebautizado recientemente como Centro de Investigaciones Biomédicas (IB) y el Centro de Biología Molecular (1975), sin duda alguna el Instituto del CSIC que más ha influenciado científicamente y organizativamente al desarrollo de la Biología Molecular en todo el país. A excepción del Centro de Investigación y Desarrollo en Barcelona, cuya evolución y diversificación han estado separados de los centros germinales de Madrid, la práctica totalidad del resto de los 13 Institutos que integran el área de Biomedicina del CSIC fueron fundados y nutridos en sus comienzos por científicos que trabajaron inicialmente en el CIB, el IIB o el CBM. Los desarrollos tempranos de la Bioquímica y la Biología Molecular en España están espléndidamente narrados en una publicación reciente (Santesmases \& Muñoz, 1997). 


\section{La investigación biomédica}

El acceso generalizado a los bancos de datos y a las nuevas formas de comunicación (Internet etc.) hacen casi obsoleta la clasificación de la actividad en Biología Experimental del CSIC en Centros y Departamentos como unidades organizativas. No es infrecuente colaborar mucho más intensamente con un laboratorio lejano que con un vecino departamental. El concepto de centros y departamentos de investigación virtuales, agrupados por convergencia de intereses más que como localización física se acabará imponiendo en el CSIC como ya lo está haciendo en muchas organizaciones estatales de investigación en Europa. Hay por tanto que considerar la situación y el futuro de la Biología Experimental en el CSIC como un todo. Pero ¿cual es esa situación?

La Biología Molecular ha sufrido en todo el mundo una rápida transformación en los últimos diez años. Ha pasado de ser una actividad semi-artesanal, concentrada en problemas muy distantes del interés público, a ser una de las nuevas tecnologías, rápidamente cambiantes, que caracterizan el final del siglo. Su revolucionaria dimensión aplicada tiene un enorme impacto económico y social. La Biotecnología ha saltado de una aplicación inicial, casi exclusivamente terapéutica de sus productos, hasta la Agricultura y el Medio Ambiente. El gran reto que afronta el CSIC es si sus formas organizativas, su inercia histórica y las muchas resistencias culturales para un cambio efectivo le permitirán subir e incluso conducir un tren que avanza rapidísimamente, o nos instalaremos en el sucursalismo y bajo perfil que resultaría de perderlo.

\section{Cinco instrumentos para la gran transición de la Biología Experimental}

Tal y como sucede con frecuencia en otras ciencias, han sido algunos desarrollos técnicos específicos los que han marcado una diferencia entre la nueva y la vieja Biología Molecular, hasta el punto de que la actividad cotidiana y las grandes referencias conceptuales en los Laboratorios de hoy día en poco se parecen a los de hace diez años. Las nuevas técnicas de alto rendimiento, la robotización y la información genómica están cambiando radicalmente el panorama y la práctica de la investigación biológica en todo el mundo.

\subsection{La reacción en cadena de la polimerasa (polymerase chain reaction o $P C R$ )}

El ya clásico artículo de K. Mullis y sus colaboradores en Science en 1985 (Saiki et al., 1985) describiendo esta técnica marca un antes 
y un después en la práctica de la Biología Molecular. La popularización del PCR no vino, sin embargo, hasta años más tarde, con la aparición en el mercado de la polimerasa termorresistente de ADN y con la comercialización de los termocicladores. La posibilidad de amplificación específica de secuencias de $\mathrm{ADN}$ a partir de muestras muy diluidas ha saltado de los laboratorios de investigación al control de alimentos, el diagnóstico, la práctica forense e incluso al espionaje (Celland et $a l .$, 1999). Los primeros termocicladores para PCR vinieron a los centros del CSIC a partir de 1989 y desde entonces no han dejado de crecer en número y en prestaciones. La técnica está ya plenamente integrada en el sistema científico español, tanto como una herramienta de investigación como de diagnóstico de todo tipo. El PCR es la base de casi todos los procedimientos actuales de secuencia automática de ADN, así como de las técnicas combinatorias y de generación de diversidad in vitro que se discuten a continuación.

\subsection{La combinatoria química/biológica}

La facilidad y abaratamiento de la síntesis química de oligonucleotidos ha permitido desde comienzo de esta década la generación in vitro de enormes repertorios de secuencias polipeptídicas, su expresión in vivo y la selección de la variantes con una actividad biológica deseada. La tecnología clave para esta aplicación ha sido el desarrollo del conjunto de métodos conocidos como presentación en fagos (phage display). Esta técnica (Amstrong et al., 1996) permite la expresión de secuencias polipeptídicas fusionadas genéticamente a las proteinas troncales o apicales de la cápsida del bacteriófagos filamentosos. La presentación del fago a una cierta diana molecular asociada a un soporte sólido facilita la separación física de la partícula capaz de interacionar con esa diana junto con la secuencia de ADN que codifica el determinante de la interacción. Los polipéptidos insertados pueden consistir en unos pocos aminoácidos, pero también en proteinas voluminosas. En este sentido, una aplicación espectacular de la técnica del phage display es la reproducción de fragmentos de anticuerpos (Fabs y Fvs) como fusiones a la proteina apical (p3) del fago M13. Esta reproducción, junto con la aplicación de técnicas combinatoriales in vitro e in vivo han permitido la generación de repertorios de anticuerpos mas diversos que los que hace el propio sistema inmune (Nissim et al., 1994) Los métodos de generar variabilidad química y biológica progresan cada día con técnicas tan sofisticadas como la presentación ribososomal (ri- 
bosomal display), que aumenta varios órdenes de magnitud la capacidad del sistema de fagos. El potencial para la investigación básica y la Biotecnología de estas técnicas es inmenso, pero muy pocos grupos de investigación en el CSIC las dominan en la actualidad.

\subsection{Los chips de $A D N$}

La combinación de la tecnología microelectrónica de chips de silicio (alternativamente, también de vidrio o de material polimérico) con la síntesis robotizada de oligonucleotidos y el PCR ha dado lugar a la tecnología emergente más notoria de los últimos años: los chips de ADN (Lipshutz et al., 1999; Vente et al., 1999). Dependiendo del tipo de chip (de genes, de oligonucleotidos, con alta o baja densidad etc), estos permiten el seguimiento de patrones complejos de la expresión génica a partir de muestras biológicas muy pequeñas la identificación rápida de mutaciones dentro de un gen e incluso la secuencia masiva y casi instantánea de segmentos de ADN (Baldwin et al., 1999; Kozian $\&$ Kirschbaum, 1999). Aunque la tecnología está aún en un estado muy incipiente, nadie cuestiona su enorme potencial. A diferencia del PCR, cuya aplicación requiere en la mayoria de los casos un equipo relativamente simple, la tecnología de los chips de ADN exige (al menos en el futuro previsible) inversiones considerables tanto en la instrumentación para producir los propios chips como como su utilización y el equipo informático para la interpretación de los datos (Gershon et al., 1997). Aunque el desarrollo del hardware para estos sistemas está fuera de las posibilidades actuales del CSIC (como lo está de la mayoría de los países), si que es realista intentar aplicaciones y adaptaciones de la metodología a problemas de ámbito más local. Esto requeriría el fomentar las interfases entre los centros de Biología Molecular del CSIC y las varias sedes del Centro Nacional de Microelectrónica.

\subsection{La automatización y robotización de operaciones de alto rendimiento (high throughput)}

El célebre manual publicado en 1982 por T. Maniatis y sus colaboradores (Maniatis et al., 1982) presentaba las técnicas básicas de la Biología Molecular como una colección de procedimientos artesanales con aparataje de bajo coste, en los que la habilidad del operario era 
crítica para el éxito. En la medida en que las necesidades instrumentales para este tipo de investigación no han sido muy sofisticadas, los Laboratorios españoles no han sufrido una gran desventaja técnica frente a los competidores internacionales. Un primer aviso del cambio fue la aparición a principios de los 90 de los equipos de alto rendimiento de secuencia de ADN y de química de proteinas, cuyos costes eran ciertamente inalcanzables para los grupos investigadores individuales y cuyo manejo requería la participación de personal técnico especializado. Muchos de estos equipos están disponibles en la mayoría de los centros de Biología Molecular del CSIC, aunque su funcionamiento óptimo requiere cambios estructurales en los Institutos que no son fáciles de implementar (ver 4.3 y 4.4). Pero el gran cambio está aún por venir con la robotización y la micro-mecanización de la mayoría de las operaciones rutinarias que en el libro de Maniatis et al. (1982) o en su secuelas posteriores (Ausubel et al., 1994; Sambrook et al., 1989) aparecen como dependientes de la pericia del científico. Los robots ya disponibles en el mercado permiten el manejo y el procesamiento de miles de muestras y multiplican masivamente la selección de colonias, la preparación de ADN, ARN o de proteínas, su secuencia, su unión a membranas y análisis de Western, Southern o Northern e incluso el seguimiento a tiempo real de ensayos de funcionalidad de miles de clones independientes. Otras técnicas más complejas (microscopía confocal, análisis de imagen, centrifugación analítica etc) van incorporando tambien un mayor componente de automatización. Robotizados o no, los nuevos métodos en Biología Experimental requerirán cada vez un instrumental más caro y sofisticado que será imposible de poseer a los grupos tradicionales de investigación en el CSIC. Por el contrario, la productividad y competitividad de los Laboratorios dependerá del uso compartido de estos equipos y de personal especializado y motivado en su manejo y programación para necesidades específicas. Al igual que la tecnología de los chips, el coste de estos equipos y su cuidado por técnicos especialistas en robótica e informática impone necesariamente cambios organizativos en los Centros de Investigación (4.3 y 4.4).

\subsection{La investigación genómica y proteómica: ¿final de la Biología Experimental?}

Existe una percepción creciente de que la terminación de la secuencia del genoma humano, precedida por la de otros muchos organismos, cierra un gran ciclo en la Biología Experimental que comenzó con la 
determinación de la estructura del ADN (Burris et al., 1998). El genoma completo de un organismo contiene toda la información sobre el mismo en términos absolutos. El gran reto actual es, por tanto, el desarrollar métodos para el manejo e interpretación de esa información y de predicción de funciones e interacciones entre las partes. Algunos incluso se preguntan si es éste el fin de la experimentación en Biología. Una vez que conocemos la base material última de los fenónemos biológicos en un organismo (la secuencia del $\mathrm{ADN}$ ) lo único que nos quedaría por explorar sería la combinación de esa información con la sobreabundancia de resultados experimentales ya disponibles. Los intentos de responder a estas cuestiones con herramientas informáticas y lingüísticas en vez de experimentales está en la base de la Ciencia Genómica o Genomics, uno de los campos de investigación más explosivos en la actualidad. La colección de nuevas técnicas que se agrupan bajo en nombre de Proteomics aspira también a un conocimiento completo de toda la dotación de proteínas de un cierto organismo, su secuencia, su estructura y sus interacciones (Blackstock \& Weir, 1999). Su origen técnico es bien distinto del Genomics, ya que procede del desarrollo de sistemas de alta eficiencia de separación de proteínas en geles bidimensionales, acoplado a espectrometría de masas. El manejo de estos equipos requiere una altísima especialización y un conocimiento multidisciplinar de química de proteinas, informática, Biología Molecular y, cada vez más en el futuro, de robótica. La incorporación del componente genómico y proteómico a todos los proyectos de investigación en Biología es otra de las revoluciones por venir y para la que se necesita de nuevo, una enorme flexibilidad intelectual y organizativa para absorber positivamente su impacto (Dove, 1999; Quadroni \& James, 1999). Si la Biología Molecular permitió el paso del in vivo al in vitro, la Ciencia Genómica y la Proteómica conduce a un tipo de experimentación in silico con una intervención material mínima del operario. Estos desarrollos están llamados a cambiar por completo el aspecto $\mathrm{y}$ actividades futuras de los Laboratorios (Williams, 1999).

\section{Los eventos movilizadores : intentos fallidos e historias de éxito}

Es ya un tópico el que los grandes avances científicos ocurren a saltos, muchas veces catalizados por situaciones de emergencia (guerras, epidemias) o por una demanda social (sida, cáncer). Desde la guerra civil hasta los años 80 apenas hubo ningún evento en España realmente 
catalizador de la opinión pública en favor de la investigación en Biomedicina, aunque si una proyección de las campañas investigadoras surgidas en los EEUU contra el Cáncer o, más recientemente, contra el SIDA.

El gran precedente fallido de movilizacion social en favor de la investigación Biológica en España fue el episodio del síndrome tóxico iniciado a finales de los 70, en el que los científicos del entonces Instituto de Enzimología del CSIC jugaron un papel importante y dieron una cierta visibilidad a la Institución. Sin embargo, la confusión inicial sobre el origen del síndrome y la imposibilidad de encontrar una cura para los afectados tuvo un efecto más negativo que positivo sobre la percepción pública de la investigación biomédica en el país.

Un segundo caso de oportunidad fallida hasta el presente es la escasa relevancia de las sociedades profesionales de Biología Experimental. La extremada atomización temática y territorial de la existentes las hacen prácticamente invisibles para la sociedad y los poderes públicos, que carecen de interlocutores científicos comparables, por ejemplo, a la AAAS o la ASM de los EEUU. El remediar esta debilidad es uno de los mayores retos pendientes para la comunidad científica de todo el Estado Español.

A pesar de estos precedentes tan lejanos de lo óptimo, el crecimiento del área Biomédica en el CSIC y su mayor aprecio social en el país ha sido manifiesto en los últimos 10 años. En esta evolución han desempeñado un papel importante algunos acontecimientos como los que se discuten a continuación.

\subsection{La integración en la CE y los Programas Marco}

La presencia de España en la CE desde 1986 ha tenido y sigue teniendo una enorme repercusión en la dinámica y los planteamientos de la comunidad científica del país. Por primera vez, los grupos activos en Biomedicina tuvieron opción, a través de los Programas Marco, de tener acceso a fuentes de financiación de una considerable magnitud. $\mathrm{El}$ precio a pagar por ese acceso era, y sigue siendo, el establecimiento de colaboraciones internacionales no siempre deseadas y el abordaje de los problemas biológicos en un contexto de aplicabilidad. En este sentido, los Programas Marco han cambiado enormemente el panorama investigador en España. Ya han pasado los años iniciales en los que los participantes del sur de Europa tenían una presencia en los proyectos europeos basada en una pura estética geográfica. En el momento actual 
el CSIC ocupa una posición más que notable en cuanto a captación recursos y participación en Proyectos de Biotecnología, Biomedicina y de Ciencias de la Vida en general. Los Programas Marco han forzado a la comunidad científica europea a desarrollar una cultura de colaboración muy distinta a la predominante anteriormente en los países individuales y plenamente vigente en los EEUU. También han dado multitud de oportunidades a los científicos jóvenes, a través de sus generosos programas de becas, para hacer sus trabajos postdoctorales en laboratorios de Europa en vez de los EEUU. Pero sobre todo, los Programas de la CE han introducido en los científicos, por la buenas o por las malas, la noción de que sus investigación, aún la muy básica, debe enmarcarse dentro de intereses sociales o empresariales específicos. Este concepto es considerablemente antagónico con la tradición académica, europea, que distingue claramente entre investigación, invención y desarrollo y en muchos casos desprecia las aplicaciones.

Muchos científicos de dentro y fuera del país han percibido negativamente los Programas de la CE como una presión intolerable para forzar la investigación básica hacia problemas mucho más prácticos. Desafortunadamente, ha habido intentos torpes en esa dirección, cuyo único resultado es fomentar una actividad colateral y científicamente irrelevante. Los Programas de la CE, por el contrario, intentan estimular la investigación de excelencia en un contexto de aplicabilidad. El dilema no es pues investigación básica o aplicada, sino investigación buena o mala. Como se discutirá mas adelante (ver 5), la clave, al menos en Biotecnología, no es empujar a la investigación fundamental hacia una solución directa de los problemas, sino crear interfases profesionales capaces de transferir eficientemente la tecnología al sector industrial y crear innovación. Esta discusión, todavía muy activa en Europa, está plenamente superada en los EEUU, donde no existen barreras legales o culturales entre la academia y la industria.

\subsection{Las reuniones (Workshops) de la Fundación Juan March}

El papel de la Fundación Juan March en el desarrollo de la Biología Molecular en España ha sido inmenso gracias, sobre todo, a la organización desde 1989 de sus ya internacionalmente famosas reuniones (Workshops) sobre temas específicos de investigación en Biología. En muchos casos las reuniones de la Fundación March han desplazado en interés a actividades consagradas como las Gordon Conferences, tal y como ha quedado reseñado en multitud de publicaciones científicas. Estas reuniones han catalizado contactos internacionales, han dado 
extraordinarias oportunidades a jóvenes científicos españoles para conseguir postdoctorales de excelencia y han elevado enormemente el status internacional de la Biología Molecular del país. Este éxito se debe no sólo a los considerables recursos económicos de la Fundación, sino también al seguimiento de criterios muy estrictos en la selección de propuestas y de participantes de las reuniones. A esto hay que añadir una organización extremadamente profesional, la limitación del número de participantes y un gran cuidado de los detalles para catalizar al máximo las interacciones científicas de todo tipo. Finalmente, los Workshops de la Fundación March han enseñado a muchos biólogos españoles la importancia de la cultura del lobby en el mundo científico. Buena parte del éxito de estas reuniones hay que atribuirla a profesionalidad y entusiasmo de una de las pocas personas citadas por su nombre en este artículo: Andrés González, Director del Centro de Reuniones Internacionales sobre Biología de la Fundación.

\subsection{La lucha contra el cáncer}

Si hay una palabra que moviliza el interés público es cáncer y todas las iniciativas al respecto reciben instantáneamente un altísimo grado de apoyo social. Las campañas tradicionales de lucha contra el cáncer, con una gran visibilidad sociopolítica, han tenido una actualización más reciente con la gran operación de regreso a España de M. Barbacid para dirigir el Centro Nacional de Investigaciones Oncológicas (CNIO). Aunque este regreso no ha estado exento de polémica, lo cierto es que ha estimulado una enorme atención y apoyo público hacia la investigación biomédica y ha puesto el escenario para la creación de una masa crítica altamente cualificada de jóvenes científicos españoles. La creación del CNIO apuesta también de relieve (una lección sin duda aprovechable por el CSIC) la importancia de las campañas de opinión dirigidas profesionalmente, las relaciones públicas y el cultivo de los medios de comunicación para dar cobertura a operaciones científicas ambiciosas. La combinación de grandes riesgos con grandes oportunidades hacen del CNIO un experimento enteramente novedoso que esta siendo seguido con enorme atención por toda la comunidad científica del país.

\subsection{La catástrofe de Aznalcóllar}

A los dos días del derrame tóxico de la mina de Aznalcóllar (25 Abril 1999), en la proximidad del Parque Nacional de Doñana, el Pre- 
sidente del CSIC tuvo la iniciativa de salir a la luz pública con la formación un grupo de expertos de la institución y de otros orígenes para responder a la situación de emergencia creada. Esa salida fue una primera respuesta a la falta de reacción por parte de las dos Administraciones implicadas y dio una visibilidad y un protagonismo enorme a los científicos del Consejo. La implicación del CSIC en todos los estudios y actuaciones posteriores ha gozado del apoyo público y de la simpatía de casi todos los estamentos sociales afectados por la catástrofe. Independientemente de la evolución de este caso, la actitud del CSIC en relación con el problema ha tenido un enorme efecto movilizador. Esto se ha reflejado tanto en el interés de la comunidad científica española e internacional por contribuir a la solución del caso (de Lorenzo \& Kuenen, 1999), como por salir a la luz pública y a los medios de la Biotecnología desde una perspectiva favorable.

Frente a algunas reacciones iniciales que aseveraban que la catástrofe no tenía ninguna solución, el CSIC preguntó desde el primer día el potencial de las técnicas biológicas para la restauración de la zona afectada. El público español escuchó por primera vez a través de los grandes medios muchos de los conceptos clave de la Biotecnología y la existencia en el país de una comunidad científica activa en el campo. Se ha transmitido con nitidez cuales serán los problemas a largo plazo que debe de afrontar la región, más allá de la propaganda tranquilizadora de las Administraciones. Se han introducido los elementos de un debate, aún por desarrollarse del todo, sobre la utilidad de las plantas transgénicas y de los organismos recombinantes, en operaciones de biorremediación ambiental. Se ha conseguido atraer la atención y el respeto de la comunidad científica internacional a las actividades del CSIC. Finalmente, la catástrofe ha originado un sistema experimental único para desarrollar nuevas tecnologías para el tratamiento de un tipo de contaminación (los metales pesados) que es el problema medioambiental número uno a escala mundial. Un efecto lateral extremadamente beneficioso ha sido el estreno en el CSIC de una iniciativa verdaderamente interdisciplinar en la que han participado ecólogos, geólogos, químicos, biólogos moleculares etc. con resultados inéditos y un enorme momentum de trabajo en equipo. Todos estos elementos han proporcionado un considerable impulso a las investigaciones sobre Biotecnología para el medio ambiente en nuestro país que deben de fructificar hacia un liderazgo en algunas de las áreas clave.

El caso de la mina de Aznalcóllar ha sido el punto de inflexión hacia una creciente confianza del público español en el CSIC como 
una institución veraz, digna de confianza y una referencia obligada en casi cualquier debate actual sobre preocupaciones públicas con contenido científico (las plantas transgénicas, las dioxinas etc.). Esta confianza, sin embargo, no debe darse por sentada y deberá evitarse cuidadosamente la implicación del CSIC en episodios tan desafortunados como la supuesta lluvia de aerolitos a comienzos del año 2000, que estuvo a punto de causar al Consejo un serio desprestigio público.

\section{La inercia organizativa}

A pesar de que la investigación Biomédica es una de las áreas mas productivas de la actividad científica en el CSIC, la posición de los estudios españoles en Biología Experimental sigue siendo modesta en el contexto internacional (Nombela, 2000). Aunque buena parte de esta situación es atribuible a la escasa inversión del PIB en investigación (que lleva consigo la inexistencia de una masa verdaderamente crítica de científicos) es la gestión y organización el auténtico cuello de botella para generar un retorno mucho más aceptable. El CSIC se ve obligado a moverse entre anquilosadas estructuras organizativas para desarrollar en nuestro pais prioridades y tecnologías que, como la Biología Molecular y la Biotecnología, cambian cada año, si no cada semana.

\subsection{Contradicciones en el sistema de financiación}

Cualquier observador externo del funcionamiento del CSIC en el contexto del sistema científico español y europeo identificaría rápidamente el conflicto entre los criterios de financiación de la actividad investigadora impuestos por la CICYT y la CE y los criterios de entrada y promoción de la carrera científica dentro del CSIC. Mientras que los primeros dependen de forma creciente de la aplicabilidad de los proyectos, la entrada en el CSIC se fundamenta exclusivamente en la excelencia de los candidatos y en sus publicaciones en revistas de alto impacto. A la vista de estos criterios, los jóvenes biólogos moleculares se plantean desarrollar investigaciones postdoctorales casi exclusivamente en laboratorios cuyas publicaciones tienen un altísimo impacto. Aunque excelencia y aplicabilidad no son incompatibles, tampoco tienen que ir necesariamente juntas. El CSIC aumenta regularmente, sobre todo en el área de Biomedicina, su plantilla de jóvenes investigadores de excelencia, pero esto no se traduce al ámbito económico o empresarial. 


\section{La investigación biomédica}

Sin embargo, la proyección sobre la sociedad de la investigación de excelencia requiere también científicos especializados, por ejemplo, en Ingeniería de Bioprocesos, una disciplina casi inexistente en el CSIC y de mucho menos impacto en la literatura. Pero el sistema funcionarial y la ausencia de una financiación propia priva a la institución de vehículos efectivos para reorientar los intereses de los investigadores una vez que ya han entrado en el CSIC. No es este un problema fácil de abordar, ya que incide en cuestiones organizativas que afectan a toda la Administración del Estado. En el mejor de los casos, muchos científicos viven el conflicto entre los criterios de financiación y de promoción profesional como un gran reto y, en el peor; como una contradicción paralizante.

\subsection{Selección del personal investigador}

La notable diferencia entre el CSIC y la Universidad Española en productividad científica, en particular en Biomedicina, es enteramente atribuible al mayor rigor en la selección del personal del que ha venido disfrutando, con altibajos, el CSIC desde mediados de los 80. En los años a caballo entre los 80 y los 90 apareció en el área de Biomedicina una oferta sustancial de plazas genéricas de Colaborador en Biología Molecular y Celular sin ningún otro perfil o especialización. Esto permitió la competencia y, finalmente, el fichaje para la Institución de un número significativo de jóvenes científicos de excelencia, por entonces postdocs en el extranjero y en muchos casos ajenos al CSIC, que iniciaron nuevos proyectos como investigadores independientes. Aunque con ciertas contradicciones (ver 4.1), la política de captar a los mejores y darles oportunidades, independientemente de ninguna otra consideración, fue la apuesta que más ha aumentado el nivel y el prestigio científico del CSIC en los últimos años. Tras el gran estancamiento y falta de liderazgo en la institución a mitad de los 90, la mejora de la situación económica y la actividad de la nueva Presidencia del CSIC a partir del 96 ha permitido más recientemente una oferta significativa de nuevas plazas de Científico Titular. El Consejo tiene otra vez la oportunidad de tomar grandes decisiones sobre las características su nuevos miembros que serán determinantes para el futuro de la Ciencia Española. La comunidad científica en Biomedicina afronta de nuevo el dilema de favorecer la consolidación de científicos jóvenes ya vinculados a grupos de investigación o la captación y apuesta pura y simple por investigadores de excelencia que generen diversificación y 
nuevas oportunidades en el área. Es éste un dilema que tiene conexiones importantes con el sistema de financiación y con las inercias culturales, pero que sin duda debe de decantarse en favor de la excelencia. El argumento de favorecer la consolidación de grupos establecidos conduce inexorablemente a un sistema de selección viciado cuyo fracaso se ha hecho bien evidente en la Universidad y cuyo impacto en el futuro del CSIC podría ser devastador. Un gran lastre cultural en este sentido es la escasa aceptación real en la comunidad biomédica española del principio de la competencia, que debería permitir una entrada regular de nueva savia investigadora en el CSIC a base de desplazar a los investigadores menos productivos. Es esta la clave del crecimiento vertical -y no horizontal- de la Institución. Los costes políticos y personales del principio de la competencia son sin embargo aún muy altos para su generalización, aunque el CSIC bien podría implementarlos en algunos de los nuevos Centros y así iniciar una nueva cultura organizativa y profesional en la Institución.

\subsection{La gestión de los centros}

No puede haber investigación de excelencia ni innovación sin una gestión avanzada de los Centros correspondientes. El CSIC arrastra también en esto una cultura que deposita el éxito de los institutos exclusivamente en la brillantez intelectual de los científicos y que cree, erróneamente, que todo lo demás se dará por añadidura. La práctica de las empresas de alta tecnología, el espejo en el que el CSIC debería mirarse organizativamente, nos dice exactamente lo contrario. La administración de los Centros, la eficiencia de los servicios de compras, los servicios técnicos, la instrumentación, el mantenimiento de los equipos, el seguimiento económico de los Proyectos, los Seminarios... son tan determinantes o más para la productividad científica como las ideas de los investigadores. La gestión de los institutos debe organizarse cada vez más profesionalmente para no ser un cuello de botella de la actividad investigadora. El perfil profesional de los gerentes de los Centros y de sus equipos debe de elevarse hasta niveles que el reglamento actual del CSIC otorga en exclusiva a los Directores. De hecho, la tendencia actual en muchos centros de Investigación europeos son las direcciones bicéfalas con un Director Científico y un Director Organizativo o Administrativo. Pero estos cambios no son triviales. En un campo tan dinámico como la investigación biomédica, las formas de gestión óptima de los Centros se convierte en sí misma en un 
objeto de investigación. Las muy criticadas plazas de investigación de gestión que ocasionalmente ha ofrecido el CSIC a miembros de equipos presidenciales cesantes podrían relanzarse con auténtico contenido investigador dentro de ese contexto de gestión avanzada de Centros.

\subsection{Crear equipos: la organización de los grupos de investigación}

Una de las grandes aportaciones de los estudios sociales sobre empresas de alta tecnología es que la productividad de los grupos de trabajo depende mucho más del estilo organizativo del equipo y de la forma en que se ejerce el liderazgo que de la calificación intelectual a secas de sus miembros (Goleman, 1998). La gestión adecuada y profesional de los recursos humanos en los grupos de investigación del CSIC es una de las mayores limitaciones para la creatividad, la innovación y la adaptación de nuestro sistema a los nuevos tiempos. Esto es particularmente cierto en Biomedicina, cuyos requerimientos de dedicación imponen al personal una intensa convivencia en el Laboratorio. El cómo convertir esa convivencia en espíritu de equipo es una de las claves de una organización moderna y avanzada. La impermeabilidad (cuando no hostilidad) de los grupos de investigación españoles a considerar alternativas organizativas que han demostrado su éxito en el mundo empresarial tiene sus orígenes en los limitadísimos modelos de identificación en los que han crecido los científicos actuales.

La investigación Biomédica en España ha tenido hasta ahora unos pocos referentes personales y organizativos que, si bien tuvieron enorme éxito en su momento, no pueden seguir considerándose modelos a seguir en una actividad tan cambiante. En particular, Ramón y Cajal, junto con Severo Ochoa y su saga de discípulos han sido los mitos y modelos de identificación en los que se han mirado muchas generaciones de jóvenes científicos españoles. Estos modelos han primado una investigación que se desarrolla completamente subordinada a las ideas y la personalidad del jefe del grupo, con poca o ninguna interacción con otros equipos, intereses o disciplinas y con una escasa o nula movilidad geográfica a lo largo de la carrera científica. Los centros pioneros del CSIC en Biomedicina (en particular el CIB y el CBM) han reflejado fielmente este modelo de Laboratorio aislado que gira en torno a un jefe autosuficiente y extremadamente territorial. A pesar de las muy notables excepciones a esta regla, es este esquema el que predominantemente se propagado a través de los Centros creados y nutridos 
originalmente por científicos del CIB y del CBM y que para muchos aparece en nuestro país como el único de las posibles.

Una presencia significativa del CSIC en las nuevas corrientes de investigación biológica exige también el desarrollo de nuevas formas organizativas de este nivel. Aunque los grupos tradicionales ha permitido mantener la ciencia de calidad en décadas de penuria, su estructura podría estar destinada al fracaso en el futuro no muy lejano. La expansión actual de la Biomedicina requiere un enorme trabajo en equipo, una interdisciplinaridad y una flexibilidad que tiene pocos precedentes en la historia del CSIC. Mientras que en el pasado un jefe podía conocer y manejar todos los aspectos de un problema biológico, la complejidad de los nuevas preguntas y técnicas exige una participación conceptual múltiple. Los grupos de investigación requerirán en el futuro estar mucho menos jerarquizados, deberán compartir recursos con otros equipos y deberán incorporar miembros y apoyos de orígenes y formación muy diversa. Se hace imprescindible la existencia de técnicos de alto nivel en los grupos y en los Departamentos, capaces de proporcionar asistencia informática y analítica especializada (secuencia de ADN, química de proteínas etc.). Y también, de forma creciente, especialistas en robótica capaces de programar y automatizar con gran eficiencia las operaciones de rutina de los Laboratorios de biología. Estos cambios sólo podrán efectuarse si en paralelo se va desarrollando en el CSIC una cultura organizativa muy distinta de la actual, mucho más horizontal, que premie la colaboración, diluya los territorios y las jerarquías, sin menoscabar los créditos individuales, y premie el cambio y las interfases con otras disciplinas.

La formación de equipos de trabajo competentes no es un problema trivial, y mucho menos en investigación, ya que el talento técnico y la brillantez intelectual no convierte por sí mismo a los científicos en buenos miembros de un grupo de trabajo. Las experiencias personales y colectivas del CSIC estan plagadas de casos de estudiantes, doctorandos y postdoctorales, brillantes individualmente, que son incapaces más tarde de trabajar sinérgicamente con otros miembros de un grupo. La investigación biológica actual, sobre todo en el gran contexto europeo e internacional, está dirigida a la consecución de objetivos dentro de un plazo. Esto requiere planificación temporal, el intercambio de información, el seguimiento de lo conseguido y la coordinación de las distintas acciones dentro de un grupo. La capacidad de interaccionar productivamente con otros colegas debe pues formar parte del currículum de los científicos profesionales del futuro casi tanto como su productividad individual. 


\subsection{Movilidad, información y presencia internacional}

La Biología molecular es una actividad cada vez más internacional que requiere una altísima movilidad y una enorme capacidad de comunicación personal con científicos de otros países. Pero esto choca con el enorme apego a lo local de nuestra cultura. Con la excepción de Madrid, la mayoría de los científicos en las otras ciudades españolas son de esa misma provincia o de los alrededores. A pesar de los indudables progresos en la última década, es infrecuente encontrar científicos que hablen lo suficientemente bien en inglés como para tener un discusión viva en una reunión internacional o para llamar por teléfono al Editor de una revista para defender una publicación. Hay poquísimos españoles senior en los grandes centros de decisión científica (pe. el EMBO Lab) y muy pocos estarían dispuestos hoy día cambiar de domicilio por un trabajo de mayor relevancia científica. Sin embargo, los investigadores tendrán que acostumbrarse finalmente a la movilidad y a cambiar de equipo y de centro en función de las prioridades del momento.

La presencia internacional es también crucial para el acceso a la información. Esta se necesita cada vez más en tiempo real, mucho antes de que aparezca por los canales tradicionales. Y esto requiere una capacidad de estar en redes profesionales donde circule la información y la experiencia por canales informales como el teléfono o el correo electrónico en un ambiente de confianza mutua. Los científicos capaces de integrarse en este tipo de redes profesionales tienen una inmensa ventaja de tiempo frente a los que no lo hacen: conocen con anticipación el trabajo de los competidores y generan nuevas ideas y oportunidades. Esta situación se hace mucho más importante en el contexto de la financiación impuesto por los Programas Marco de la $\mathrm{UE}$, donde la formación de equipos internacionales donde impere el flujo de información y la confianza es un requisito para el éxito. Típicamente, los consorcios que participan en los proyectos de la UE se forman y disuelven en función de unos objetivos tangibles (deliverables) que han de conseguirse en un periodo de tiempo definidos (hitos o milestones). La capacidad de formar y desarrollar con éxito este tipo de equipos requiere una capacidad de interacción y de gestión profesional mucho mas cercana a la dinámica empresarial que a la tradición académica europea. Y sin duda originará nuevos modelos de identificación sobre el quehacer científico muy distintos a los actuales. 


\section{Insuficiencias de los sistemas vigentes de transferencia de tecnología}

Los vehículos de transferencia al sector industrial para la investigación en Biología Molecular y Biotecnología no son muy distintos de los de otras ciencias en el CSIC. Un cierto trabajo de investigación da lugar a una patente y durante el proceso (y a veces con un preacuerdo), una empresa nacional o multinacional expresa un interés en su explotación comercial. Los beneficios que genera esa explotación pueden retornar a la institución en forma de pagos directos de royalties al CSIC (incluyendo un porcentaje para el investigador) o en forma de convenios de investigación entre las partes. En general, este vehículo es deficiente y no explota ni moviliza todo el potencial investigador y generador de innovación de la institución en Biomedicina.

No existe en el país una cultura de interacción fluida entre la investigación básica y la empresa, mucho menos en el caso de la Biología Molecular. Es difícil motivar a los científicos de excelencia a proyectar su investigación en áreas aplicadas, sobre todo cuando los retornos no son evidentes. La gran empresa española, sobre todo aquella que más se beneficiaría de una Biotecnología avanzada (la empresa farmacéutica, el sector agronómico y medioambiental) es extremadamente conservadora y con poca visión estratégica. La Biología Molecular y la Biotecnología avanzan a velocidad muchísimo más rápida que la capacidad de las empresas españolas para entenderlas y beneficiarse de esos progresos. Es muy difícil explicar a los usuarios potenciales las claves biológicas de los nuevos productos y procesos.

Una alternativa al modelo vigente de transferencia de tecnología es el fomento de las empresas spinoff, nacidas del ámbito académico, tal y como se desarrollaron en los EEUU en los 80s y que se empiezan a generalizar también en Europa. El avance de estas empresas en nuestro país requiere no sólo un cambio en la legislación que permita a los científicos de plantilla el promover actividades empresariales, sino también un cierto cambio cultural que anime a los investigadores jóvenes, a contemplar su futuro profesional en empresas de cierto riesgo. Sólo la exploración de nuevas vías como ésta permitirá una transvase eficiente de conocimientos y recursos que permita a nuestro país el tener una actividad empresarial de altura en productos biotecnológicos y un cierto mercado de trabajo no-académico para los científicos formados en el CSIC. 


\section{La investigación biomédica}

\section{Conclusión}

A pesar de los innegables avances de la Biología Experimental en el CSIC, el cambio generacional experimentado por la institución no se ha traducido aún en un cambio organizativo ni de las formas de trabajo que garanticen la relevancia de la investigación biomédica española en un escenario futuro extremadamente cambiante. Aunque los cuellos de botella son perfectamente identifić'olles, su solución choca con la inercia cultural y las tradiciones de buena parte de su personal científico. El avanzar desde la situación presente requerirá un buen grado de valentía y visión política para vencer esas inercias organizativas mediante la introducción técnicas avanzadas de gestión de los recursos científicos, humanos y materiales inspiradas en el mundo empresarial. La comunidad de Biólogos Moleculares de la institución tiene la capacidad científica sobrada para hacer contribuciones decisivas al campo, pero necesita instrumentos organizativos y de transferencia de tecnología que superen los límites actuales. Sólo entonces, las apariciones de la Biomedicina española en la ciencia internacional dejaran de ser ocasionales para integrarse en la corriente principal de la investigación de excelencia en el mundo industrializado.

\section{Bibliografía}

Armstrong, N., Adey, N. B., McConnell, S.J. and Kay, B.K. (1996): Vectors for phage display. En Phage display of peptides and proteins. Kay, B.K., Winter, J. and McCafferty, J. (eds.) San Diego: Academic Press. pp. 35-53.

Ausubel, F.M., Brent, R., Kingston, R.E., Moore, D.D., Seidman, J.G., Smith, J.A. and STruHL, K. (1994): Current Protocols in Molecular Biology. New York: John Wiley \& Sons.

Baldwin, D., Crane, V., Rice, D. (1999): A comparison of gel-based, nylon filter and microarray techniques to detect differential RNA expression in plants. Curr. Opin. Plant Biol. 2: 96-103.

Blackstock, W. P., Weir, M. P. (1999): Proteomics: quantitative and physical mapping of cellular proteins. Trends Biotechnol 17: 121-127.

Burris, J., Cook-Deegan, R., Alberts, B. (1998): The Human Genome Project after a decade: policy issues. Nature Genetics 20: 333-335.

Clelland, C.T., Risca, V. and Bancroft, C. (1999): Hiding messages in DNA microdots. Nature 399: 533-534.

DE Lorenzo, V. y Kuenen, G. (1999): Scientific basis for the remediation of the toxic spill of the Aznalcóllar mine: combining bacteria and plants to address an intractable kind of pollution. Enviromental Microbiology 1: 275-278.

Dove, A. (1999): Proteomics: translating genomics into products? Nature Biotechnology 17: $233-236$. 
Gershon, D., Sobral, B.W., Horton, B., Wickware, P., Gavaghan, H., Strobl, M. (1997): Bioinformatics in a post-genomics age. Nature 389: 417-422

Goleman, D. (1998): Working with emotional intelligence. Bantam book, New York.

Kozian, D. H., Kirschbaum, B. J. (1999): Comparative gene-expression analysis. Trends Biotechnol 17: 73-78.

Lipshutz, R. J., Fodor, S. P., Gingeras, T.R., LockharT, D.J. (1999): High density synthetic oligonucleotide arrays. Nature Genetics 21(1 Suppl): 20-24.

Mantatis, T., Fritsch, E. F., and SambrooK, J. (1982): Molecular cloning: A laboratory manual. Cold Spring Harbor Laboratory. Cold Spring Harbor, NY.

Nissim, A., Hoogenboom, H. R., Tomlinson, I. M., Flynn, G., Midgley, C., Lane, D., Winter, G. (1994): Antibody fragments from a single pot phage display library as immunochemical reagents. EMBO J. 13: 692-698.

NomBela, C. (2000): Página web http://www.csic.es/hispano/presid11.htm. Informes del National Science Board, Science \& Engineering Indicators-1998 U.S. Government Printing Office y Second European Report on S\&T Indicators, 1997. European Commission.

QuADRon, M., JAMES, P. (1999): Proteomics and automation. Electrophoresis 20: 664-677.

Saik, R.K., Scharf, S., Falloona, F., Mullis, K., Horn, G.T. Erlich, H. A. y Arnheim (1985): Enzymatic amplification of $\beta$-globin genomic sequences and restriction site analysis of diagnosis of sickle cell anemia. Science 230: 1350-1354.

Sambrook, J., E. F. Fritsch, y T. Maniatis. (1989): Molecular cloning : A laboratory manual. Cold Spring Harbor Laboratory. Cold Spring Harbor, NY.

SANTesmases, M. A. y MuÑoz, E. (1997): Establecimieto de la bioquímica y de la biología molecular en España. Fundación Ramón Areces y Consejo Superior de Investigaciones Científicas, Madrid.

Vente, A., Korn, B., Zehetner, G., PoustKa, A., Lehrach, H. (1999): Distribution and early development of microarray technology in Europe. Nature Genetics 22: 22.

Williams, K. L. (1999): Genomes and proteomes: towards a multidimensional view of biology. Electrophoresis 20: 678-688. 